\title{
Introduction To This Special Issue On Marine Renewable Energy
}

TWENTY-ONE YEARS AGO, I stepped off a plane in Prince William Sound, Alaska, to begin one of the most difficult, yet rewarding jobs of my career with the National Oceanic and Atmospheric Administration (NOAA). I was there to provide scientific support for the cleanup of the Exxon Valdez spill. Today, I am overseeing NOAA's response to the Deepwater Horizon spill in the Gulf of Mexico. These events remind us that there are human and environmental risks to producing and delivering energy. They also help shake the world to look for new ways of creating energy.

As we turn to the ocean to explore possibilities for new power sources, it is exciting to contemplate creating clean and renewable energy from the planet's winds and seas. Doing it properly will require sound science, testing, debate, funding, policy, and guidance. The very heart of this effort calls for a serious commitment to protect the lives and health of people, wildlife, and our ocean and coastal habitats.

When NOAA staff was asked to guest edit this special issue of Oceanography, we welcomed the prospect. NOAA has played a role in energy for many years as a steward for our nation's oceans and coasts. One of our goals is to ensure that energy exploration, production, and transport in the ocean and coastal zone are environmentally responsible and comprehensively planned, respecting the needs of other ocean users. With over $50 \%$ of the nation's population living in coastal counties and over half of the nation's gross domestic product being generated in coastal counties, demands on our coastal and ocean spaces are great. As we consider the creation of new clean energy jobs, we need to ensure that existing jobs are protected, including jobs in ocean-dependent industries such as fishing, marine transportation, and coastal tourism.

Marine renewable energy is an important and timely issue. The authors contributing to this special issue come from many areas of the marine renewable energy arena-academia, industry, federal and state government, social science, and commercial fishing. They discuss the state of knowledge and the uncertainty about different types of marine energy and some of the barriers to commercial-level production. They share lessons from other nations that have more experience with wind and wave energy. One of the articles features an analysis of the current federal regulatory process for marine energy. Other articles highlight the human and biological considerations of marine energy development. In the op-ed section, four writers offer their personal experiences on the importance of engaging stakeholders in this complex process.

I would like to thank the authors and reviewers who dedicated their time and knowledge to this special issue. I'd also like to thank our partners in this project, particularly Oregon State University and The Oceanography Society, for giving NOAA the opportunity to help further this vital discussion of marine renewable energy.

David M. Kennedy, Acting Assistant Administrator for Ocean Services and Coastal Zone Management, National Oceanic and Atmospheric Administration 